\title{
International Conference on Virtual Learning - ICVL 2006
}

The current issue of the journal contains seven extended papers published in the "Proceedings of the 1st International Conference on Virtual Learning, October 27 - 29, 2006, Bucharest, Romania, (ICVL 2006)" (M. Vlada, G. Albeanu \& D.M. Popovici eds.).

The first edition of the International Conference on Virtual Learning - ICVL 2006 was organized by University of Bucharest, Faculty of Mathematics and Computer Science in association with European INTUITION Project (The INTUITION Network of Excellence in Europe - http://www.intuition-eunetwork.net/) and in conjunction with the fourth National Conference on Virtual Learning - CNIV 2006 to celebrate one hundred years from the birth of the great Romanian mathematician and "Computer Pioneer Award" of IEEE Computer Society (1996) - Grigore MOISIL (1906 - 1973).

The ICVL was structured to provide a vision of European e-Learning and e-Training policies, to take notice of the situation existing today in the international community and to work towards developing a forward looking approach in Virtual Learning from the viewpoint of modelling methods and methodological aspects (M\&M), information technologies (TECH) and software solutions (SOFT). The conference has established a large area of topics to cover the following subjects, but not limited to: Innovative teaching and learning technologies, Web-based methods and tools in traditional, online education and training, Collaborative e-Learning, e-Pedagogy, Design and development of online courseware, Information and knowledge processing, Knowledge representation and ontologism, Cognitive modelling and intelligent systems, Algorithms and programming for modelling, Advanced distributed learning technologies, Web, virtual reality/AR and mixed technologies, Mobile e-Learning, communication technology applications, Computer graphics and computational geometry, Intelligent virtual environments, New software environments for education and training, Streaming multimedia applications in learning, Scientific web-based laboratories and virtual labs, Soft computing in virtual reality and artificial intelligence, Avatars and intelligent agents.

Initially 72 abstracts were received and 55 of them were selected. Finally only 34 papers were accepted for presentation at the ICVL and publication in Proceedings of the ICVL - Bucharest University Press (ISBN 978-973-737-218-5).

Participants coming from Europe, Japan, Australia and Canada have discussed various aspects concerning the future developments in the virtual learning field during the conference. Four invited papers talking about trends in professional learning, time series modelling, analysis and forecasting in e-Learning environments, AeL - the e-Learning Universal Platform and, the teaching through projects methodology have been presented as plenary lectures. Ten papers proposed different software solutions, while twenty papers were dedicated to modelling methods and methodological aspects.

Some ICVL papers are considered for publishing in the current issue of the International Journal of Computers, Communications and Control. Let us present an introduction of the selected papers.

The paper of A. Andreatos is dedicated to define and classify the Virtual Communities and their Importance for Informal Learning, and to examine their social impact and resulting trends in technology management. A bibliographical review, and some case studies illustrate the aforementioned tasks.

A. Anohina, in her paper, considers the intelligent tutoring systems (including architecture topics based on two layers approach) powered by adaptive support for learners in order to solve practical problems. 
The Minimax algorithm is considered as a practical illustration.

The paper of N. Doukas and A. Andreatos presents a computer-aided assessment system (e-Xaminer; a web-based interface system) based on parametrically designed questions that uses meta-language concepts to automatically generate tests.

In their paper, I. Kitagaki and his colleagues, present an algorithm for groupware modelling for a collaborative learning environment using mobile terminals. They show not only the grouping algorithm but also some considerations about discussion in a classroom.

M. Lambiris presents the concepts and a technique used to design a methodology for providing individualised computer-generated feedback to students. Such an approach can also be used to provide detailed and high accuracy information to the instructor about the performance of the whole group.

The paper of G. Moise describes a software system for online learning using intelligent agents (an execution agent and a supervisor agent) and conceptual maps. Experimental results are also considered.

M. Oprea presents in her paper a multi-agent system design procedure to be applied for universities course timetable scheduling that is a difficult administrative task. A preliminary evaluation of the proposed multi-agent system is presented in order to show the benefits obtained when a university uses such an approach.

Considering the successful story of the ICVL 2006 event, the scientific community shows great interest to the second edition (ICVL 2007: 26-28th of October) that will take place at OVIDIUS University of Constanta, Romania.

Grigore Albeanu Guest editor

ICVL Technical Program Chair UNESCO Chair in Information Technologies University of Oradea, University Street, No. 1 410087, Oradea, Bihor, Romania 